CUADERNOS DE ESTUDIOS GALLEGOS, LX Núm. 126 (enero-diciembre 2013), págs. 337-358

ISSN: 0210-847 X

DOI: 10.3989/ceg.2013.126.09

\title{
UN SABIO MÉDICO GALLEGO: DON JACOBO LÓPEZ ELIZAGARAY (1860-1934)
}

Fernando J. Ponte Hernando

Servicio Galego de Saúde

ISABEL REGo LIJÓ

Sonia González Castroagudín

Universidad de A Coruña 


\section{UN SABIO MÉDICO GALLEGO: DON JACOBO LÓPEZ ELIZAGARAY (1860-1934)}

\section{RESUMEN}

Retrato biográfico de don Jacobo López Elizagaray, una de las más destacadas figuras de la Escuela Médica Compostelana acreditada en Madrid. Auténtico maestro de la Medicina interna del último tercio del siglo XIX y primero del XX, pionero en la modernización de la Medicina española, fue maestro y compañero de destacadísimas personalidades médicas gallegas y de toda España, como los Dres. Varela y Varela, Santiago Carro García, Nóvoa Santos, Gómez Ulla, Marañón, Jiménez Díaz, Goyanes Capdevila, Varela Radío y muchos otros.

Palabras Clave: Hospital Provincial, Madrid, Real Academia Nacional de Medicina, Armada, Centro Gallego.

\section{UN SABIO MÉDICO GALEGO: DON JACOBO LÓPEZ ELIZAGARAY (1860-1934)}

\section{RESUMO}

Retrato biográfico de don Jacobo López Elizagaray, unha das máis destacadas figuras da Escola Médica Compostelana acreditada en Madrid. Auténtico mestre da Medicina Interna do último tercio de século XIX e primeiro do XX, pioneiro na modernización da Medicina española, foi mestre e compañeiro de moi salientables personalidades médicas galegas e de toda España, como os Dres. Varela e Varela, Santiago Carro García, Nóvoa Santos, Gómez Ulla, Marañón, Jiménez Díaz, Goyanes Capdevila, Varela Radío e moitos outros.

Palabras Clave: Hospital Provincial, Madrid, Real Academia Nacional de Medicina, Armada, Centro Galego.

\section{A WISE GALICIAN DOCTOR: DON JACOBO LÓPEZ ELIZAGARAY (1860-1934)}

\section{Abstract}

Biographical Portrait of don Jacobo López Elizagaray, one of the most prominent figures of Compostelan Medical School accredited in Madrid. True master of Internal Medicine of the last third of the nineteenth and twentieth first, pioneer in the modernization of Spanish medicine, was teacher and fellow of extraordinarily distinguished medical personalities from Galicia and from all Spain, as Drs. Varela y Varela, Santiago Carro García, Nóvoa Santos Gómez Ulla, Marañón, Jimenez Diaz, Goyanes Capdevila, Varela Radio and many others.

KeY words: Provincial Hospital, Madrid, Royal National Medical Academy, Navy, Galician Center. 
Recibido/Received: 25/02/2013

Aceptado/Accepted: 19/08/2013

Es estúpido burlarse sin ton ni son del enciclopedismo y no creer obreros útiles en el progreso científico más que a los pincharranas y cuentagotas ${ }^{1}$.

Miguel de Unamuno

\section{La Escuela Médica Compostelana}

A la hora de hablar de la que se ha dado en llamar Escuela Médica Compostelana, en realidad, habría que hacerlo de, al menos, tres componentes de la misma:

1.- La residente en Compostela, articulada en torno a dos grandes núcleos, la Facultad de Medicina y el Gran Hospital Real, fundado por los Reyes Católicos a principios del siglo XVI, con sus dos partes: Hospital Clínico y de Beneficencia, con frecuencia, enfrentadas.

2.- La desplazada y asentada en Madrid, compuesta en general de catedráticos como Varela Radío ó Nóvoa Santos, Académicos como Santiago Carro García (1889-1966), destacado miembro del Instituto Rubio; médicos militares y altos funcionarios, como médicos de Cámara del Rey; o que reunían ambas circunstancias, entre ellos: Varela y Varela, Gómez Ulla y López Elizagaray; o médicos de grandes hospitales, como el propio López Elizagaray y de Institutos Sanitarios Nacionales como José Goyanes Capdevila, entre otros.

3.- La de la diáspora, ya sea la de quienes se fueron por traslados o haber ganado cátedras fuera de Galicia, como Juan José Barcia Goyanes en Valencia; o Patricio Borobio en Zaragoza; o la lista enorme y distinguida de los que, pasando un tiempo en Compostela que marcó, en mayor o menor medida, una impronta en su trayectoria y estilo, acabaron su vida académica en distintas universidades; o bien por el doloroso exilio, tras la contienda civil de 1936-1939.

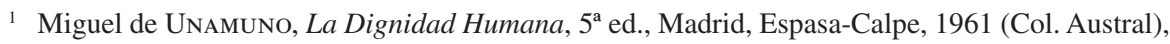
pág. 16.
} 


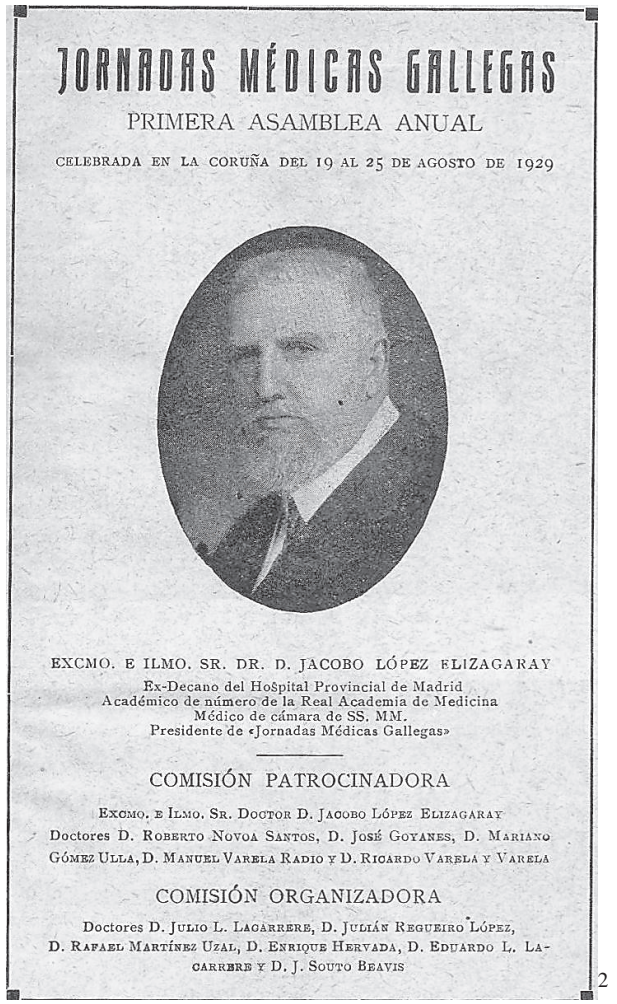

Fig. 1
En cuanto a la parte madrileña, la nómina es extensa e ilustre: el gran urólogo ${ }^{3}$ Dr. Varela y Varela, decano de los médicos de Cámara de Alfonso XIII; don Santiago Carro, gastroenterólogo de fama, Jefe de la Sección de aparato digestivo del Instituto Rubio y miembro de la Real Academia Nacional de Medicina; el internacionalmente prestigioso cirujano monfortino don José Goyanes Capdevila, precursor de la moderna cirugía oncológica; los catedráticos don Roberto Nóvoa Santos, introductor en España de las corrientes fisiopatológicas europeas, auspiciadas por Ludolf von Krehl y don Manuel Varela Radío, catedrático de obstetricia, modernizador de la cirugía ginecológica; el General don Mariano Gómez Ulla, cirujano ilustre, Académico de la Nacional y Presidente del Consejo General de Colegios de Médicos y muchos más.

Hemos citado al Dr. Varela y Varela, médico de Alfonso XIII y hablaremos, en esta ocasión, de un compañero suyo en esas labores que, también era, como Varela, compostelano y médico de la Armada por oposición, aunque no llegó a ejercer en ella por circunstancias un tanto curiosas, el Dr. D. Jacobo López Elizagaray.

Desgraciadamente, casi todos los miembros de la Escuela Compostelana fueron muy poco amigos de publicar sus conocimientos, con honrosas excepciones, como: Nóvoa Santos, Gil Casares, Barcia Caballero, Goyanes Capdevila o, entre los no gallegos que pasaron por la Universidad Compostelana, Eduardo García del Real, por ejemplo. Don Juan Barcia Caballero, auténtico grafomaníaco, escritor médico, literato, columnista y poeta, autor de la letra del Himno al Apóstol

\footnotetext{
2 Portada de la I Asamblea anual de las Jornadas Médicas Gallegas de 1929, presididas por don Jacobo López Elizagaray.

3 Al decir del Dr. Eduardo Hervada García-Sampedro. Vid. Andrés Martínez Morás, Semblanzas raciales, Madrid, Espasa-Calpe, 1930, pág. 196.
} 
Santiago, llamaba a esto la idiosincrasia antipublicista de sus compañeros de claustro ${ }^{4}$.

\section{NACIMIENTO}

Don Jacobo nació en la calle del Preguntoiro núm. 23 de Santiago de Compostela a las 4 de la tarde del 13 de Octubre de 1860, siendo bautizado y recibiendo los santos óleos al día siguiente ${ }^{5}$, de manos del sacerdote don Buenaventura Eyras de las parroquia de San Fiz ${ }^{6}$ de Solovio y Santa María Salomé. Fueron sus padres don Domingo López Lorenzo y doña Josefa Elizagaray Jauriquiverri ${ }^{7}$.

\section{BACHILLERATO}

Acabó el bachillerato en Santiago el 30 de Octubre de 1874, con la calificación de aprobado, siéndole expedido el título el 13 de mayo de 1875.

\section{EN LA FACUltad DE MEDiCina ${ }^{8}$}

Estudió, con éxito, la carrera de Medicina en la secular Fonseca, terminando en 1880, y presentándose al grado de Licenciado el 14 de junio de ese año. Fue convocado el día 17 del mismo mes para realizar el primer ejercicio, en el que resultó declarado apto para pasar al segundo que se celebró al día siguiente, consistiendo, en una primera parte, en diagnosticar un cáncer de estómago, y en una segunda de ejercicio operatorio sobre cadáver. Formaron el tribunal que lo examinó del grado, don Ángel Botana como Presidente, don Manuel Piñeiro, vocal y don Jesús Novoa López, secretario. Obtuvo la calificación de aprobado con esa misma fecha de 18 de junio de 1880, por tanto 4 meses antes de cumplir los 20 años.

Es de señalar que quién luego sería un prestigioso facultativo, terminó con dos únicos sobresalientes en la carrera, en Anatomía II y Patología quirúrgica II.

Se doctoró en Madrid el 20 de enero de 1885, con la tesis: Diagnóstico de los tumores cerebrales.

\footnotetext{
4 Vid. Fernando J. Ponte Hernando, Isabel Rego Lijó, La Locura y el Bisturí: I Centenario de D. Timoteo Sánchez Freire, Santiago de Compostela, Seminario Mayor de San Martín Pinario; Servicio de Publicaciones Universidade de Santiago de Compostela; Asociación Cultural Rocha Forte, 2012.

5 Fol. 76 v. del libro octavo de bautizados de San Félix de Solovio y Santa María Salomé: Archivo Histórico Universitario de Santiago, Legajo 713, Expediente 1.

6 San Félix.

7 En el documento manuscrito de la partida de bautismo, es dudosa la inicial de este segundo apellido, entre "L", "Y" y "J".

8 Archivo Histórico Universitario de Santiago, Legajo 713, Expediente 1.
} 


\section{MÉdico DE LA ARMADA9}

De los manuscritos que conforman su hoja de Servicios en la Marina, parece deducirse una curiosa circunstancia.

Todo indica que ganó la oposición de ingreso, recibiendo la formación militar correspondiente a un oficial médico, en 1881. Con fecha 13 de julio de dicho año aparece un documento en que se le nombra Médico $2^{\circ 10}$, sin sueldo ni antigüedad, pasando a una especie de lista de espera de incorporación al servicio, hasta el 29 de mayo de 1885 , en que se le asciende de Médico $2^{\circ}$ provisional a efectivo y, seguidamente, el 11 de junio de 1885 se le destina al servicio de guardias del Hospital Militar de San Carlos (Cádiz) ${ }^{11}$.

El 30 de Julio oficia, por encontrarse enfermo, sin haberse incorporado al destino, pero, según se hace constar en otro documento, sí se había presentado en el Ministerio de Marina el 1 de Junio, pasando la revista administrativa y no llegando, al parecer, a incorporarse al servicio activo. En septiembre de $1885^{12} \mathrm{se}$ le concede la baja en la Armada por enfermedad. Alegaba presentar amigdalitis recidivantes, cuadro clínico complejo de curar en la era preantibiótica.

La posible explicación la tenemos en el hecho de que, en 1884, Jacobo ingresó por oposición como médico de guardia ${ }^{13}$ en el Hospital Provincial de Madrid $\mathrm{y}$, dado que no le llamaban para incorporarse a la Armada, y, teniendo en cuenta además de su enfermedad, el gran prestigio del Hospital; quizás hubiese encauzado ya su vida profesional por este camino.

\section{MATRIMONiO Y FAMiLiA}

Don Jacobo tuvo, al menos, una hermana, Juana, casada en 1894 con don Gerardo Curros $^{14}$, y tres hermanos varones, Francisco, nacido en Compostela el 24 de mayo de 1870, Licenciado en Medicina por la Universidad de Santiago con Sobresaliente el 23 de febrero de 1893, opositó a médico militar, llegando a teniente coronel, y jubilándose en Junio de 1931. Sus hijos oficiales del ejército

\footnotetext{
9 Archivo General de Marina Álvaro de Bazán, Viso del Marqués (Ciudad Real), Gpo. Sanidad Militar, 2898-85.

${ }^{10}$ Equivalente a Teniente.

${ }^{11}$ La Correspondencia de España: diario universal de noticias, 14 de junio de 1885, pág. 3.

${ }^{12}$ La Unión: diario democrático de la mañana, 19 de septiembre de 1885, pág. 3.

${ }^{13}$ Su ficha de la Real Academia dice que como Jefe de Sala, Zulaica afirma lo contrario poniendo en boca del Dr. Álvarez Sainz de Aja que la oposición de Jacobo López Elizagaray fue a Médico de Guardia. Codina la data en 1885 y Zulaica en 1884. Vid. Daniel Zulaica ArIsti, Vida y obra del Dr. Madinaveitia, Guipúzcoa, Diputación Foral, 1985, pág. 63.

${ }^{14}$ El Anunciador, diario de noticias, anuncios e intereses morales y materiales, 2 de Marzo de 1894, pág. 2.
} 
fueron asesinados por militantes de izquierdas durante la guerra civil de 1936$1939^{15}$.

Luis, prestigioso pedagogo, profesor y Director de la compostelana Escuela Normal de Maestros, figura importante del Ateneo León XIII, autor de diversos trabajos de corte pedagógico, con incursiones en el mundo literario. Por último, Rafael que, al parecer, falleció joven, siendo Profesor Auxiliar de la Escuela de Artes y Oficios.

Jacobo contrajo matrimonio con Dolores López Ferreiro ${ }^{16}$ hermana del afamado intelectual y canónigo de la Catedral de Santiago, don Antonio López Ferreiro (1837-1910) autor de la Monumental Historia de la S.A.M.I. Catedral de Santiago, y director de los trabajos que llevaron a la recuperación de los huesos del Apóstol en 1879.

Veraneaban habitualmente en la casa familiar de San Pedro de Vilanova (Vedra), conocida como Pazo de Galegos, dónde falleció el ilustre sacerdote y polígrafo, a las tres de la madrugada del 20 de marzo de $1910^{17}$.

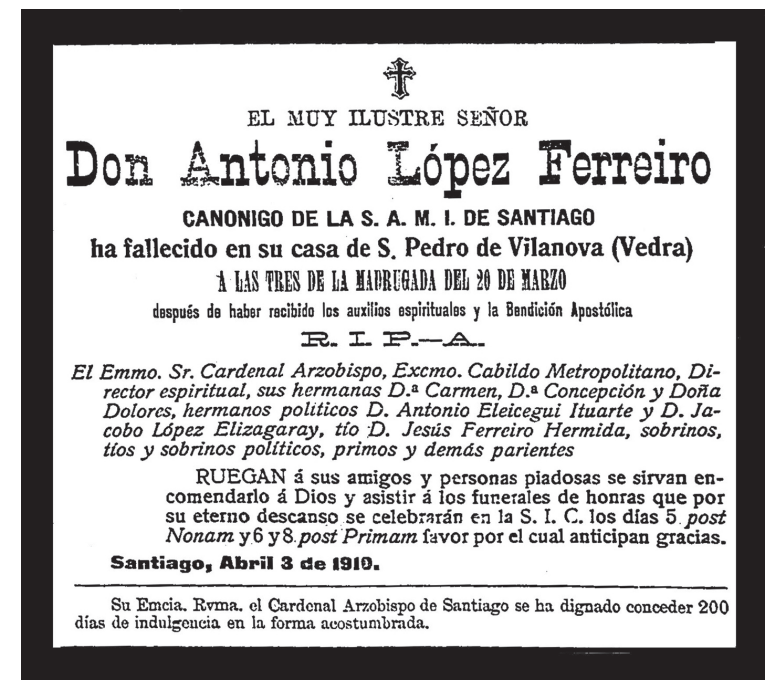

Fig $2^{18}$

\footnotetext{
${ }^{15}$ Archivo General Militar de Segovia, Expediente de don Francisco López Elizagaray.

${ }^{16}$ Gaceta de Galicia, diario de Santiago, decano de la prensa compostelana, 20 de Julio de 1888.

${ }^{17} \mathrm{Su}$ fallecimiento causó honda conmoción en Compostela, donde se le tributaron numerosos homenajes y sus exequias resultaron enormemente solemnes por la asistencia de numerosas autoridades de todos los ámbitos. Las presidió el Obispo auxiliar y fue inhumado en el ala norte del claustro catedralicio.

${ }^{18}$ Esquela de don Antonio López Ferreiro, dónde se aprecian los nombres de sus parientes, entre ellos don Jacobo: Diario de Galicia, 3 de abril de 1910.
} 


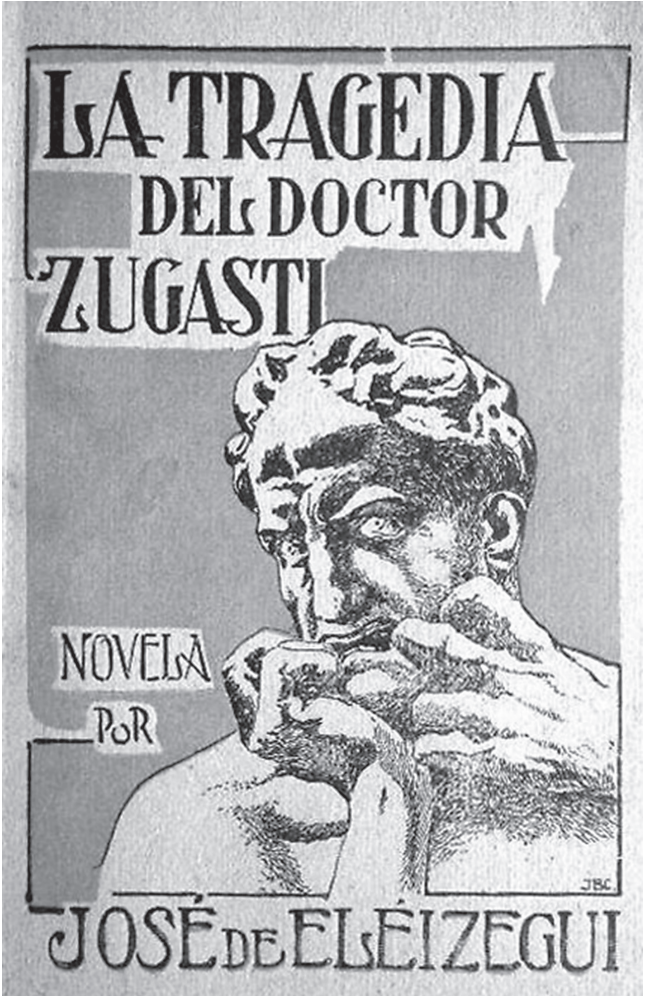

Fig. 3

Dolores y Jacobo tuvieron una sola hija, María Josefa que contraería matrimonio con el Capitán de Artillería don Jesús López Varela $^{19}$, quien alcanzaría el Generalato, matrimonio este que vivió parte de su vida en Santiago.

Otra hermana de don Antonio López Ferreiro, Carmen $(+1916)^{20}$, estaba casada con el Ingeniero don Antonio Eléizegui Ituarte $(+1914)^{21}$ y fueron padres del Dr. D. José Eléizegui López.

José Eléizegui ${ }^{22}$ (1879-1956), natural de Santiago, sobrino de don Jacobo, fue un Pediatra también pedagogo y maestro nacional- Catedrático de Higiene Escolar en la Escuela Nacional de Puericultura de Madrid. Se doctoró en la Universidad Central en 1920 con la tesis: Contribución al estudio del criterio fisiológico en Medicina.

Fundador y Director de España Médica (1911-1936), revista profesional de la época, fue también redactor médico de Heraldo de Madrid (1890-1939) y ha sido considerado como el renovador del periodismo médico moderno español. Estuvo muy atento siempre a las actividades de su tío.

\footnotetext{
${ }^{19}$ El Correo de Galicia, diario independiente de avisos y noticias, 19 de febrero de 1919, pág. 2.

${ }^{20}$ España Médica, 20 de julio de 1916, pág. 1. España Médica comienza a publicarla en uno de febrero de 1911, primero con periodicidad decenal, después quincenal y a partir de 1931 con frecuencia mensual. Su paginación y formato varía, desde las 16 hasta las 40 páginas, según aumenta su frecuencia de aparición, así como su composición, de las tres a las dos columnas. Será un periódico de información científica-profesional e ilustrado, al incorporar un buen número de fotograbados en sus entregas.

${ }^{21}$ España Médica, 20 de febrero de 1914, pág. 1. Don Antonio fue Ingeniero jefe de Orense y Coruña, Inspector general, miembro del Consejo de Minería y director de la fábrica de gas de Santiago. Hombre polifacético, publicó ensayos sobre ciencia y trabajos sobre aguas minerales y minería. ${ }^{22}$ Andrés Martínez Morás, Semblanzas raciales, Madrid, Espasa-Calpe, 1930, pág. 164-166.
} 
Siempre interesado en el mundo del niño, publicó obras pedagógicas y divulgativas como: De crianza infantil; Educando al niño, los juegos en la infancia, La Educación física del niño, La sexualidad infantil: normas de Educación; Biología de la edad escolar y Visita al médico. También obras más generales: La familia y los enfermos: Enseñanzas higiénicas; Nociones de Higiene Industrial, Higiene del agua; Difteria (Epidemiología, diagnóstico clínico y tratamiento) y otras.

Hizo alguna incursión en el mundo de la literatura como en La tragedia del Dr. Zugasti ${ }^{23}$, de carácter bondadosamente satírico.

Eléizegui, alumno predilecto de don Maximino Teijeiro, prologó con la biografía de este su obra póstuma sobre el tratamiento de la sífilis. Con motivo del descubrimiento del Salvarsán, logró reunir a muchos médicos para homenajear a Paul Ehrlich.

\section{En el Hospital Provincial de Madrid}

En 1884-85, como hemos dicho, el joven Jacobo había obtenido, en reñida oposición, una plaza en el hospital de la Beneficencia Provincial de Madrid, dónde ejerció, de por vida, la medicina interna y la Jefatura de la Sala de Enfermedades del Pecho. Era un extraordinario clínico, con dedicación preferente a la patología cardiopulmonar. Llegó a ser brevemente Decano del Hospital, ya que le alcanzó la jubilación en estas funciones ${ }^{24}$, siendo sustituido por don José Codina Castellví, que le dedicó cumplidos elogios en su toma de posesión ${ }^{25}$ y que también había contestado su discurso de ingreso en la R.A.N.M años atrás. Refiriéndose a la oposición de Elizagaray al Hospital Provincial, el Dr. Codina dijo:

Y llegó el ansiado momento. Era el año de 1885, cuando se anunciaron a oposición unas vacantes en el Cuerpo de la Beneficencia Provincial, que por su deslumbrante historia cientifica y humanitaria y por el relieve de sus inolvidables figuras, ha sido en toda época un centro de libre enseñanza, de contraste profesional y de poderosa atracción para toda la juventud estudiosa y de gran valía. Los más prestigiosos nombres de la juventud médica firmaron las oposiciones y se aprestaron a la fiera y descomunal batalla, que siempre fueron las oposiciones al Hospital General, por la

\footnotetext{
${ }^{23}$ José de Eléizegui, La tragedia del Doctor Zugasti, Barcelona, Ed. Luis Gili, 1921.

${ }^{24}$ Vid. D. Zulaica Aristi, Vida y obra... pág. 129.

${ }^{25}$ Diario $A B C$ de 8 de noviembre de 1929, ed. de la Mañana, pág. 22.
} 
propia reputación de los opositores, actos reñidísimos y severos, como pocas veces se ve en las oposiciones a cátedra ${ }^{26}$.

Efectivamente, en la oposición de Elizagaray iban contendientes como Giol del Valle, Jaime Vera, Juan Bravo, García Mansilla o Juan de Azúa, que también obtuvo plaza y llegaría a ser el más famoso dermatólogo español. Allí, Jacobo trabajó con gran éxito y el reconocimiento general, que le valieron el ser nombrado Profesor Agregado de Clínica Médica de la Facultad de Medicina, magnífico medio de entonces para integrar en el profesorado a los mejores clínicos, como Madinaveitia, Valle Aldabalde, él mismo y muchos otros.

También formó parte de numerosos tribunales de oposiciones a los más diversos cuerpos médicos y académicos, como Competente, figura esta correspondiente a un médico que había de reunir determinadas condiciones reconocidas.

\section{Médico y Decano del Hospital de San José y Santa Adela}

Los primeros tiempos del, luego boyante, Hospital Central de la Cruz Roja San José y Santa Adela, fueron ajetreados. Merece la pena comentarlos brevemente.

En 1887 una dama acaudalada dejó fondos para hacer un hospital para chicas del servicio doméstico afectadas de cáncer, nombrando albacea y administrador del mismo a su médico de cabecera doctor don Eduardo Castillo del Piñero ${ }^{27}$. Rápidamente se levantó una elegante edificación, diseñada por el arquitecto don José Marañón, siguiendo el sistema de pabellones, rodeadas de un jardín verdaderamente variado en especies arbóreas. Al terminar la obra se acabó el capital fundacional y quedó todo abandonado. Tras un intento fallido de los famosos dres. Pulido y Cortezo, no se consiguió corregir este estado de cosas, hasta 1913.

Por influencia de la Reina Madre $\mathrm{D}^{\mathrm{a}} \mathrm{M}^{\mathrm{a}}$ Cristina, se constituyó un Patronato dirigido por una Junta de Damas que obtuvo fondos del Gobierno, Ayuntamiento, Obispado y Diputación y que abrió el hospital dirigiéndolo a sus fines originales. Se nombró Director a don Jacobo López Elizagaray y Subdirector al cardiólogo don Baudilio López Durán y siete profesores ${ }^{28}$ médicos de guardia.

Cuando mejor funcionaba el hospital, la Reina Madre tuvo noticia de que algunas de las damas flirteaban por los jardines con sus admiradores y cerró el hospital inmediatamente, siendo trasladadas las enfermas a su Real cargo a las

\footnotetext{
${ }^{26}$ José Codina CAStellvi, "Contestación al discurso de Ingreso en la RANM de D. Jacobo López Elizagaray”, en España Médica, 20 de junio de 1920.

27 O Piñeyro, según otros.

${ }^{28}$ La denominación de profesores a los médicos era muy común en la Beneficencia.
} 
salas de pago del Hospital de la Princesa. Hasta que en 1921 la Duquesa de la Victoria, ejemplo de la Enfermería española, se fue a África, dónde libraban nuestras tropas la cruenta guerra, y, en unión del Dr. Víctor Manuel Nogueras, mandó traer los heridos al hospital, ahora llamado de la Cruz Roja, que se abrió inmediatamente para este fin, bajo la dirección del Dr. Nogueras, siendo subdirectores los dres. Luque y Serrada ${ }^{29}$.

\section{Médico de la Real CÁmara}

Don Jacobo fue también Médico de Cámara de Alfonso XIII, en cuyo cargo, entre otras muchas tareas, tuvo en sus manos - por ausencia del Dr. D. Ricardo Varela y Varela, que estaba en Londres con el Rey Alfonso XIII- la atención, en sus últimos momentos, de la Emperatriz de los franceses, la española Da Eugenia de Montijo $^{30}$ (1826-1920), vda. de Napoleón III, que murió de un ataque de uremia en el Palacio de Liria, propiedad de sus parientes de la Casa de Alba, en Madrid, con 94 años cumplidos.

Aún cuando los clínicos de la época seguían siendo grandes generalistas, el hecho de ser Varela, urólogo, Elizagaray, especialista en enfermedades cardiopulmonares, y Gómez Ulla, cirujano, obligaba a que se efectuaran mutuamente frecuentes llamadas a consulta, que recoge la prensa en los partes clínicos de las reales personas.

En cumplimiento de sus obligaciones consta que, entre otras cosas, acompañaba a los reyes en sus vacaciones, como médico de jornada, alternándose con los otros médicos de Cámara, lo que recoge en portada El Heraldo Alavés, de 1 de Agosto de 1928, que lo sitúa ese verano en Santander con SS.MM.

Asimismo atendió hasta su fallecimiento ${ }^{31}$ al ilustre jurista y político gallego, don Eugenio Montero Ríos ${ }^{32}$.

\section{Gran Cruz de Beneficencia}

El Rey Alfonso XIII concedió a don Jacobo, en 1928, la Gran Cruz de la Orden Civil de Beneficencia, con distintivo morado y blanco, que le fue impuesta a principios del año siguiente.

\footnotetext{
${ }^{29}$ Extractado y modificado de José Álvarez Sierra, El doctor Blanco Soler y su época, Madrid, Ediciones y publicaciones españolas S. A., 1964, págs. 83-88.

${ }^{30}$ De soltera, María Eugenia Palafox Portocarrero y Kirpatrick, Condesa de Teba.

${ }^{31}$ Gaceta de Galicia, diario de Santiago, decano de la prensa compostelana, 15 de Mayo de 1914.

${ }^{32}$ La Correspondencia de España, diario universal de noticias, 12 de Mayo de 1914.
} 


\section{Numerario de la Real Academia Nacional de Medicina}

Resultó elegido Académico Numerario de la Real de Medicina por unanimidad el 28 de junio de 1917, con ocasión del fallecimiento del Dr. Ortega Morejón, a propuesta de los Dres: Carracido —el sabio farmacéutico y químico compostelano, que llegó a Rector de la Universidad Central, y ocupaba una de las plazas que a estas profesiones se les reservaba en la Real Academia Nacional de Medicina ${ }^{33}$ - Codina, Isla, Huertas Barrero y Cisneros, y leyó su discurso de ingreso el 23 de Mayo de 1920, acerca de: Crisis agudas de insuficiencia cardíaca, enfermedad de la que fallecería él mismo, el 1 de Octubre de 1934.

La contestación al discurso corrió a cargo, como dijimos, del ilustre tisiólogo Dr. Codína Castellví. ${ }^{34}$ Don Jacobo quedó adscrito a la Sección de medicina y especialidades médicas, dónde cuajó una gran labor, ostentando la medalla núm. 48.

\section{La Revista Clínica de Madrid}

El doctor Elizagaray, fue fundador de esta revista quincenal especializada, en la que se publicaron importantes aportaciones científicas originales de la clínica española. Fundada en enero de 1909, por destacados catedráticos y profesores de la Facultad de Medicina de Madrid, que al mismo tiempo ejercen sus especialidades en los Hospitales General, de la Princesa y San Juan de Dios o en el Instituto Rubio o el Nacional de Higiene Alfonso XIII.

Entre ellos destaca el más prestigioso de los dermatólogos españoles, el citado catedrático de Madrid, Juan de Azúa Suárez (1858-1922), acompañado, además de por don Jacobo, por profesores médicos, como Juan Madinaveitia (1861-1938) y cirujanos como José Ortiz de la Torre (1858-1928), León Cardenal y Pujals (1878-1960) y el renombrado cirujano monfortino José Goyanes Capdevila (1876-1964).

Hay que citar además al malogrado neurocientífico, psiquiatra e Histólogo, Nicolás Achúcarro Lund (1880-1918), discípulo querido de Cajal ${ }^{35}$, el catedrático de Terapéutica y Farmacología Teófilo Hernando Ortega (1881-1976), íntimo de Gregorio Marañón (1887-1960), con el que emprenderá la aventura editorial del Manual conocido como “el Hernando y Marañón”, primero de medicina

\footnotetext{
${ }^{33}$ Don José Rodríguez Carracido, ingresó en la Real Academia Nacional de Medicina como Académico de número, con destino a la Sección de Farmacología y Farmacia el 4 de febrero de 1906, con el discurso: «Farmacodinamia de los modificadores de la oxidación orgánica». En nombre de la Academia le contestó don Juan R. Gómez y Pamo. Su incursión literaria en La Muceta roja, Madrid, Imprenta de Fortanet, 1890, nos parece, sencillamente, plúmbea

${ }^{34}$ España Médica de 20 de junio y 1 de Julio de 1920 recoge el discurso del Dr. Codina Castellví, eminente tisiólogo.

${ }^{35}$ Enriqueta Lewy Rodríguez, Así era Cajal, 1ª ed., Madrid, Espasa-Calpe, 1977 (Col Austral).
} 
interna hecho íntegramente por españoles; el parasitólogo italiano, naturalizado español, Gustavo Pittaluga (1876-1956); y el pionero de la cirugía gástrica nacional, discípulo de Madinaveitia, Luis Urrutia y Guerezta (1876-1930), todos destacadas figuras científicas de la llamada Edad de Plata de la Cultura española.

Marañón, era entonces profesor auxiliar y médico del Hospital General de Madrid, y presentó en esta revista sus primeros trabajos clínicos y experimentales, compartiendo además ${ }^{36}$, la jefatura de redacción con Miguel Gayarre Espinel (1866-1936), director de los manicomios de Ciempozuelos.

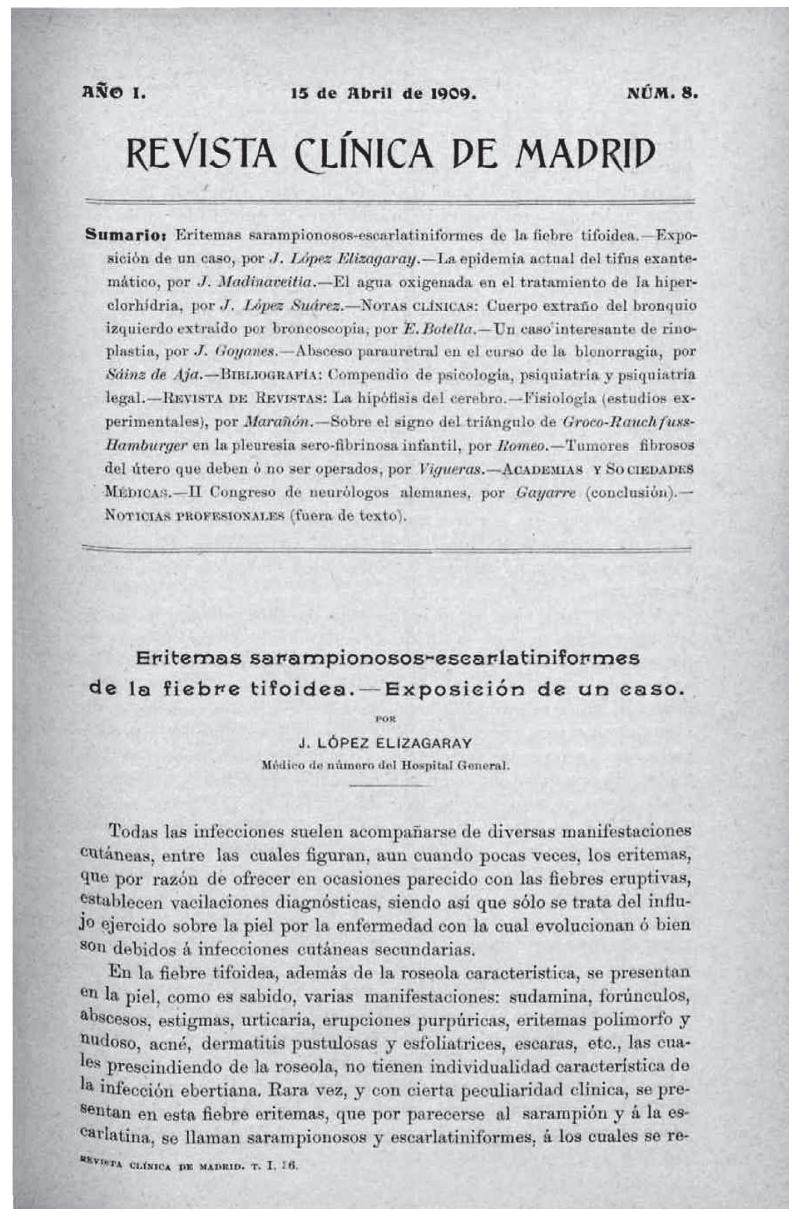

Fig $4^{37}$

\footnotetext{
${ }^{36}$ Desde Julio de 1914.

${ }^{37}$ Portada de trabajo de don Jacobo en Revista Clínica de Madrid.
} 
Gayarre era un psiquiatra de formación alemana, discípulo de don Santiago Ramón y Cajal, que presentará la primera aportación española a las controversias psicoanalíticas, en el artículo: La génesis sexual del histerismo y de las neurosis en general $^{38}$, de neto rechazo a las teorías freudianas, publicado en el primer número de la revista.

Después de 7 años de salir puntualmente, tras llegar al público el número de diciembre de 1915, la revista fue absorbida por la veterana cabecera de El Siglo Médico (1854-1936) ${ }^{39}$, que fundara don Serapio Escolar ${ }^{40}$.

\section{Publicaciones de dON JACOBo López Elizagaray}

Fundador, como decimos, de la Revista Clínica de Madrid, Elizagaray publicó poco. En su época fue, sin duda, uno de los profesionales más acreditados de Madrid y de toda España, como afirma Sánchez Granjel ${ }^{41}$. Algunos de sus trabajos son comentarios a obras de autores extranjeros. Hemos encontrado los siguientes:

1885. Diagnóstico de los tumores cerebrales. Tesis Doctoral.

1901. Discurso leído en la sesión inaugural del año académico de 1901-1902 en la "Sociedad Española de Higiene".

1902. Discurso leído en la sesión del año académico de 1902 a 1903 en la "Academia MédicoQuirúrgica española" celebrada el día 17 de noviembre de $1902^{42}$.

1909. "Eritemas sarampionosos-escarlatiniformes de la fiebre tifoidea. Exposición de un caso". Rev. Clin. de Madrid. Año 1. Núm. 8.15 de abril. (Fig. 4)

1909. "Dos casos de Hematemesis apendicular". Rev. Clin. de Madrid. Año 1. núm. 1, pág.13. 1909. "Nuevas orientaciones en el diagnóstico y profilaxia de la fiebre tifoidea". Rev. Clin. de Madrid. 1 de marzo. Año 1. Núm. 5, pág. 15.

1909. "Los cuerpos inmunizantes de Carl Spengler y su nuevo producto antituberculoso". Rev. Clin. de Madrid. 1 mayo. Núm. 9, pág.18.

1909. "Pulso lento permanente de origen intracardíaco". Rev. Clin. de Madrid. 1 mayo. Núm. 9, pág. 22.

1914. "El tratamiento de la pulmonía por el suero antidiftérico". Rev. Clin. de Madrid. 15 de julio. Núm. 13, pág. 24.

1920. Crisis agudas de insuficiencia cardíaca, discurso de ingreso en la "Real Academia Nacional de Medicina".

\footnotetext{
${ }^{38}$ Revista Clinica de Madrid, Año I, núm. 1 (1 de Enero de 1909).

39 Vid. Hemeroteca Nacional Digital.

40 José Álvarez Sierra, Historia de la Medicina Madrileña, Madrid, Editorial Universitaria Europea, 1968, pág. 119.

${ }^{41}$ Luis. S. Granjel, Historia General de la Medicina Española, vol. V: Medicina Española Contemporánea, Salamanca. Ed. Universidad, 1986.

${ }^{42}$ El Siglo Médico, semanario, 23 de noviembre de 1902, año 49, núm. 2554, pág. 1.
} 
1929. "Diagnóstico precoz de la Insuficiencia cardíaca y síndromes de su estado latente." I Jornadas médicas gallegas. Agosto. Ed. Instituto IBYS. Págs. 99-102.

\section{Maestro de Maestros}

En su discurso de 1920, refiriéndose a 1896, el Dr. Codina, que era entonces opositor a plaza del Hospital General, siendo don Jacobo miembro del tribunal, lo describe como:

Un buen mozo, alto, con carnes sin obesidad, ágil de frente recta, con profundas entradas, cabeza redonda y pequeña, como artístico estuche que contuviera condensada y seleccionada materia, adornado con pelo y barba rizosos, cara ligeramente aplastada, con ojos no por chicos, de mirada menos suave y escudriñadora, con finos ademanes y la sonrisa siempre dispuesta a asomar en sus labios ${ }^{43}$.

Treinta y cuatro años después, el periodista gallego Martínez Morás ${ }^{44}$ en su libro Semblanzas Raciales, que recoge perfiles de médicos gallegos ilustres, afincados en Madrid, lo ve así:

Alto, robusto, corpulento; con cabeza troglodítica y hercúleo torso, D. Jacobo, dulcemente, con ademán compasivo, va viendo a sus enfermos ${ }^{45}$.

Durante el curso 1891-1892, don Jacobo tuvo como residente a Juan Madinaveitia Ortiz de Zárate, que sería fundador de la especialidad de Aparato Digestivo en España, y uno de los grandes maestros de la generación de Marañón, lo que afirmará este en numerosas ocasiones. Posteriormente, también tuvo a su cargo formándose a Pío Baroja y a Carlos Jiménez Díaz ${ }^{46}$. Sus ocupaciones eran tantas que en España Médica de 1 de Enero de 1915, el Dr. Eléizegui, que usaba el pseudónimo de Dr. Cauterio, ironizaba con ofrecer regalos de Reyes a diversos médicos, dedicándole a don Jacobo: un aeroplano para llegar a todos los sitios de dónde lo llaman. Sin embargo, Elizagaray no formó discípulos con

\footnotetext{
43 José Codina Castellvi, "Contestación al discurso de Ingreso en la RANM de D. Jacobo López Elizagaray", en España Médica, 20 de junio de 1920.

${ }^{44}$ Hijo de A. Martínez Salazar, Presidente de la Real Academia Gallega y padre de Carlos Martínez Barbeito, Presidente de la Academia Gallega de Belllas Artes.

${ }^{45}$ Andrés Martínez Morás, Semblanzas raciales, Madrid, Espasa-Calpe, 1930, pág. 30.

46 Daniel Zulaica, Vida y obra... pág. 61.
} 
una clara impronta, Álvarez Sierra lo incluye, con Espina y Capó, Valle y Aldabalde, Ortiz de la Torre y otros, entre los maestros de excepcionales méritos, que no dejaron la escuela personal que hubieran podido ${ }^{47}$.

\section{En Asociaciones y JoRnadas MÉdicas}

Don Jacobo fue Secretario general de la Academia Médico-Quirúrgica Española ${ }^{48}$, Consiliario de la Sociedad Española de Higiene y fundador y Vicepresidente de la Sociedad Española de Especialistas en Enfermedades del Pecho ${ }^{49}$. También fue presidente, como vimos, de las I Jornadas Médicas Gallegas, de 1929, además de Presidente honorario de los Congresos de la Tuberculosis de Zaragoza, en 1908, y Barcelona de 1910; así como de las II jornadas Médicas Gallegas de 1931. En las terceras, en 1933, fecha en que ya Elizagaray estaba muy enfermo, Martínez Morás, propuso:

Lanzar para que sea recogida por quienes deban hacerlo la idea de rendir un homenaje de admiración y cariño al varón bueno y justo, al clínico prestigioso, presidente de las primeras Jornadas Médicas Gallegas, Dr. Jacobo López Elizagaray, venerable patriarca de la medicina galaica, quién por sus méritos incontables, por su optimismo profesional y su gran amor a Galicia, merece la más reverencial de las distinciones ${ }^{50}$.

El Dr. López Elizagaray tomó parte en el concurso de Premios de la Sociedad Española de Higiene de 1887, en el primer tema, de carácter obviamente pediátrico: La Higiene del trabajo en la segunda infancia, don Jacobo, internista ilustre, sólo cedió consiguiendo un accésit por detrás del brillante pediatra y periodista don Manuel Tolosa Latour ${ }^{51}$ (1857-1919) que sería, antes que Elizagaray, académico de la Nacional de Medicina.

El 16 de diciembre de 1901, don Jacobo, como Consiliario de la misma Sociedad, bajo la Presidencia del Ministro de la Gobernación fue encargado del discurso inaugural de curso académico, lo que anunció la prensa días antes ${ }^{52}$.

\footnotetext{
47 José Álvarez Sierra, Historia de la Medicina Madrileña..., pág. 119.

${ }^{48}$ Leyó la memoria del año anterior en la apertura del curso 1902-1903. Diario El Imparcial, 17 de noviembre de 1902.

49 España Médica, 20 de diciembre de 1915.

${ }^{50}$ España Médica, 1 de Agosto de 1933, pág. 22.

${ }^{51}$ La Época, diario vespertino, 24 de Noviembre de 1887, pág. 2.

${ }^{52}$ La Época, diario vespertino, viernes 13 de Diciembre de 1901.
} 


\section{Con los Médicos gallegos en MAdRID}

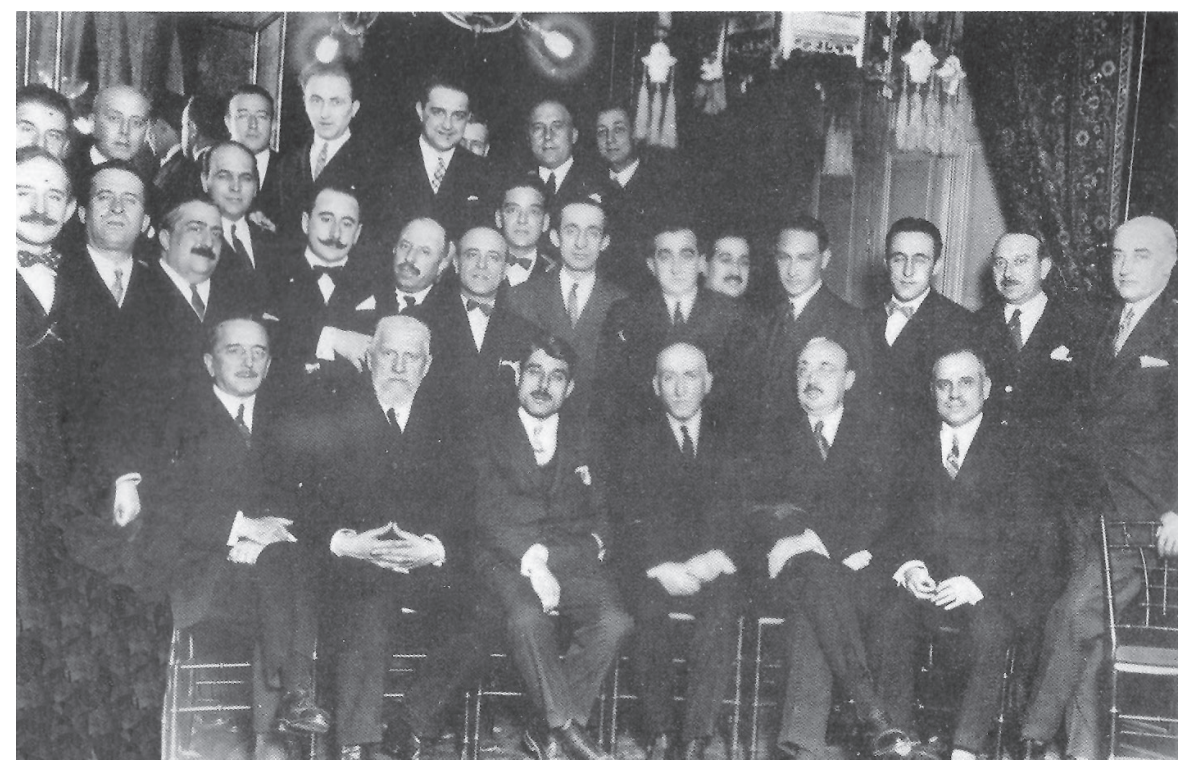

Fig 5

1928. Homenaje a Nóvoa Santos. Sentados de izda. a derecha: Dr. Varela y Varela, médico de Alfonso XIII, detrás de él el Dr. Eléizegui; con barba blanca don Jacobo López Elizagaray, don Roberto Nóvoa Santos, ¿??, Dr. Varela Radío, detrás de él Dr. D. Julio López Lacarrere, ¿?; de pie, primero por la derecha, el Dr. D. Mariano Gómez Ulla.

A primeros de 1928, tuvo lugar en Madrid un gran homenaje al nuevo catedrático gallego de Patología General de la Universidad Central, don Roberto Nóvoa Santos. De ese acto presentamos esta foto, en la que don Jacobo ocupa lugar preferente, junto al homenajeado.

\section{El Dr. Elizagaray en la literatura troyana}

En la novela póstuma de Alejandro Pérez Lugín, Arminda Moscoso, el recordado Adolfo Pulleiro, Panduriño--que en La Casa de la Troya aparecía como un estudiante de Medicina pobre, que se pagaba los estudios actuando en verano como cornetín de charanga en las fiestas de villas y aldeas-aquí ya tiene un Sa- 
natorio y trata al tío del héroe anticaciquil y novio de Arminda, Asorey, a quién está muy agradecido porque:

\begin{abstract}
$V d$. Me recomendó a D. Jacobo López Elizagaray y me presentó luego a Mariano Gómez Ulla ${ }^{53}$ en aquel consulado gallego de La Tropical, para que practicase con ellos y aprendiera a su lado lo mucho que podian enseñarme" ${ }^{54}$.
\end{abstract}

\title{
El Centro Gallego y La Gallega, Casa de Salud
}

Don Jacobo fue Vicepresidente y vocal del Centro Gallego de Madrid en numerosos mandatos.

En 1897 resultó elegido vicepresidente quinto en las elecciones celebradas a principios de año ${ }^{55}$, en 1902, vicepresidente tercero ${ }^{56}$ y, en 1903, vicepresidente segundo ${ }^{57}$, cargo que ostentaría también, al menos, en 1916.

Contribuyó a la puesta en marcha del Centro Gallego y La Gallega, una Casa de Salud.

Los fines humanos, benéficos, educativos y sanitarios del Centro Gallego, ciertamente loables, y avanzados socialmente, para el marco de la época $\operatorname{eran}^{58}$ :

1. Instrucción gratuita conforme a los modernos principios pedagógicos ${ }^{59}$.

2. Asistencia Sanitaria a sus socios en una Casa de Salud que se instalará como las mejores de su clase existentes en el extranjero.

3. Consulta médica gratuita en el local de la Casa de Salud.

4. Socorro pecuniario a los socios enfermos que necesiten volver a la tierra natal.

\footnotetext{
${ }^{53}$ Mariano Gómez Ulla (1877-1945). Eminente Cirujano militar nacido también en Compostela, Académico de la Nacional de Medicina y General de División, que fue Inspector General de Sanidad del Ejército y Presidente del Consejo General de Colegios Médicos de España. Estuvo comisionado como observador médico en las dos Guerras Mundiales.

${ }^{54}$ La Noche, diario de la tarde, 5 de mayo de 1948. Alejandro PÉrez Lugín, Arminda Moscoso, Madrid, Librería y Casa Ed. Hernando, 1928, pág. 79.

55 Diario El Día, 6 de Enero de 1897.

${ }^{56}$ La Correspondencia de España, diario universal de noticias, 25 de diciembre de 1902.

${ }^{57}$ Diario El Imparcial, 22 de junio de 1903, pág. 4.

${ }^{58}$ Gaceta de Galicia, diario de Santiago, decano de la prensa compostelana, 8 de Junio de 1900, pág. 2.

${ }_{59}$ Posiblemente esta redacción aludía a los principios de la Institución Libre de Enseñanza.
} 
5. Protección al trabajo procurando colocación a los socios inscritos que lo necesiten.

6. Consulta gratuita de Letrados en los locales que pueda tener la asociación.

7. Recreo y esparcimiento en los salones del Centro, en los cuales habrá juegos lícitos y diversiones honestas.

8. Lectura de libros, obras de ciencia, literatura y artes, revistas y periódicos.

En 1904, se inauguró la Casa de Salud ${ }^{60}$, La Gallega, que establecieron los gallegos residentes en Madrid en un cómodo hotelito alquilado, en la calle Zurbano 55, esquina Abascal, dónde los socios del Centro Gallego y los naturales de Galicia recibían asistencia médica gratuita de gran calidad por parte de 15 prestigiosas figuras de la medicina y cirugía madrileñas, entre ellas, además de Elizagaray y otros, don José Goyanes Capdevila. Tenía sala de operaciones ${ }^{61}$ y de consultas, baños, cocinas, comedor, capilla y habitaciones para enfermos, todo muy cuidadosamente instalado.

El 29 de Julio de 1913 aparece en La Voz de la verdad una noticia un tanto desconcertante, visto lo anterior, titulada: "El Centro Gallego de Madrid. Un consultorio hospital". En ella se recoge que la ponencia, para la creación de esa importante mejora, quedó constituida bajo la Presidencia de don Jacobo en lo que atañe a la Sección de Medicina y por don Federico Come, la de Cirugía. Este equipo lo integraban cirujanos tan expertos como Mariano Gómez Ulla y el zamorano Laureano Olivares Sexmilo ${ }^{62}$ auténtico maestro de la cirugía de la época.

\footnotetext{
${ }^{60}$ Periódico Diario de Pontevedra, 5 de Mayo de 1904, pág. 1.

${ }^{61}$ Hay que tener en cuenta que el primer Sanatorio Quirúrgico de Galicia, el de los Dres. Baltar Cortés y Varela Radío, no se inauguraría en Santiago hasta 1908. vid. Fernando J. Ponte HernanDo, Ángel Baltar Cortés (1868-1934) Maestro de Cirujanos, A Coruña, Ed. Inéditor, 2011 (Col. Scripta).

${ }^{62}$ Olivares fue premio Extraordinario de Licenciatura y doctorado por la Facultad de Medicina de Madrid. Médico por oposición de la Beneficencia Municipal (1904). En los años siguientes fue Jefe de Casas de Socorro y Cirujano del Equipo Municipal de Madrid. Director del Servicio de Cirugía en el Cuerpo de la Beneficencia Provincial.Profesor Auxiliar y posteriormente Catedrático, por oposición y por unanimidad del tribunal, de Patología Quirúrgica en la Facultad de Medicina de Madrid (1917). Cirujano en el H. Clínico de San Carlos y en el H. General de la Beneficencia Provincial. Fue un Clínico Quirúrgico incomparable y un experto Cirujano, una de las figuras más sobresalientes de la Medicina española del siglo XX. Visitó las clínicas extranjeras y asistió como ponente a diversos Congresos y reuniones. Ficha modif. de la Real Academia Nacional de Medicina.
} 


\section{ANTIBEXIS}

Una cosa llamativa, a los ojos de hoy en día, es la costumbre, no mal vista en la época, de que afamados médicos, con frecuencia catedráticos, como Gil Casares, Nóvoa Santos o Novo Campelo, aconsejasen en la prensa especialidades farmacéuticas publicitarias. Elizagaray, al igual que don Manuel Tolosa Latour recomendaba este específico para el tratamiento de la tos y expectoración.

\section{ANTIBEXIS}

Dice el Dr. Elizagaray, profesor encargado de a sala de enfermedades del pecho en el Hospita: Jeneral de Madrid:

Sr. D. T, Gonzklez,-Biarritz.

Muy señor mio: He ensayado en mi clínica de TUBERCULOSOS del Hospital General su pre jarado de GUAYACOL y TERPINOL, y en efec 0 , he conseguido en muchas ocasiones calmar la lOS y modificar la EXPECTORACION, de ta iuerte que esta preparación que Vd. denomina INTIBEXIS puede recomendarse en las BRON. 2UITIS, especialmente FEMICAS, en la seguri lad de obtener Ios más lisonjeros resultados.

En virtud de mis observaciones, me complazcc in comunicarle mi favorable juicio acerca de la itilísima preparación de que os Vd. autor, que lando de Vd. atento s. s. q. b. s. m.,

\section{Diciembre ron}

JACOBO LOPEZ ELIZAGARAY.

De venta en las principales farmacias.

Fig. $6^{63}$

\section{El Instituto Audet: UNA ANÉCDOTA CURIOSA}

En la primavera-verano de $1889^{64}$, este Instituto Médico policlínico privado, Hotel de Salud, dirigido por el Dr. R. Audet Solsona, se anunciaba con gran aparato publicitario, como "celular y antiséptico" (sic) en la calle de Ferraz 66, con todos los medios diagnósticos y terapéuticos de moda y multitud de lujos y prestaciones, citando a don Jacobo entre sus especialistas - en enfermedades del estómago y vías digestivas - cosa un poco extraña, colaboración que este desmintió enseguida, públicamente, en la prensa ${ }^{65}$.

\footnotetext{
${ }_{63}^{63}$ Diario El Imparcial, 8 de Enero de 1902.

${ }^{64}$ Véanse los diarios El Día, La Iberia o La República en los meses de Mayo y Junio de 1889.

${ }^{65}$ La Correspondencia de España, diario universal de noticias, 8 de junio de 1889, pág. 2.
} 


\section{Muerte De dON JACOBO}

A partir de los setenta años al Doctor Elizagaray, se le agravó la insuficiencia cardíaca que padecía hacía tiempo, lo que soportó con resignación. El día 1 de octubre de 1934 falleció este hombre modesto y sencillo, de gran estatura moral y científica y sólido relieve profesional. En la sesión necrológica celebrada en su memoria por la Real Academia de Medicina, el 23 del mismo mes de octubre, tanto el Presidente de la Corporación, don Amalio Gimeno Cabañas, Conde de Gimeno $^{66}$, como los ilustres académicos Dres. Alvarez Ude, Simonena y Marañón pusieron de manifiesto las altas dotes del difunto y el profundo dolor que su pérdida significaba ${ }^{67}$. Su sillón lo ocupó ${ }^{68}$ don Ramón de Luis Yagüe, ilustre gastropatólogo, sucesor de don Federico Rubio y Galí, al frente del Instituto de Técnica Quirúrgica y Operatoria, que, a su muerte, se denominó Instituto Rubio.

El Dr. Eléizegui dedicó, en su triple condición de Médico, sobrino, y Director de España Médica, unas bellas páginas necrológicas a don Jacobo en el número de 1 de Octubre de $1934^{69}$, en ellas dice:

La vida del Dr. Elizagaray merece ser biografiada extensamente. Fue una vida rectilínea que trazó la austeridad del deber, sin desviarle en nada ni pasiones ni conveniencias de ningún género. Por eso hay que hacerla conocer en todos sus detalles, para que constituya ejemplo firme de un proceder honrado y de un trabajo sin mancha.

Esperamos haber contribuido un poco a ello.

\section{BIBLIOGRAFÍA ${ }^{70}$}

Álvarez Sierra, José, El doctor Blanco Soler y su época, Madrid, Ediciones y Publicaciones Españolas S.A., 1964.

Álvarez Sierra, José, Historia de la Medicina Madrileña, Madrid, Editorial Universitaria Europea, 1968.

Codina Castellví, José, "Contestación al discurso de ingreso en la R.A.N.M. de D. Jacobo López Elizagaray”, en España Médica, 20 de junio de 1920.

Granjel, Luis S., Historia General de la Medicina Española, vol. V: Medicina Española Contemporánea, Salamanca. Ed. Universidad, 1986.

\footnotetext{
${ }^{66}$ Catedrático de Patología General, ocho veces ministro y mentor de Ferrán.

${ }^{67}$ Modificado de Archivo de la Real Academia Nacional de Medicina.

${ }^{68}$ Boletín de la Revista Ibero-Americana de Ciencias Médicas, núm. 102 (Nov. 1934), pág. 6.

${ }^{69}$ España Médica, 1 de Octubre de 1934, págs. 7-8.

${ }^{70}$ Agradecemos su apoyo a todo el personal de la Biblioteca Xeral de la Universidade de Santiago de Compostela y al de los Archivos Álvaro de Bazán y General Militar de Segovia.
} 
Martínez Morás, Andrés, Semblanzas Raciales, Madrid, Espasa-Calpe, 1930.

Pérez Lugín, Alejandro, Arminda Moscoso, Madrid, Librería Casa Ed. Hernando, 1928.

Ponte Hernando, Fernando J., Ángel Baltar Cortés (1868-1934) Maestro de Cirujanos, A Coruña, Ed. Inéditor, 2011 (Col. Scripta).

Ponte Hernando, Fernando J., Rego Lijó, Isabel, La Locura y el Bisturí: I Centenario de D. Timoteo Sánchez Freire, Santiago de Compostela, Seminario Mayor de San Martín Pinario; Servicio de Publicaciones Universidade de Santiago de Compostela; Asociación Cultural Rocha Forte, 2012.

Lewy Rodríguez, Enriqueta, Así era Cajal. 1ª ed., Madrid, Espasa-Calpe, 1977 (Col Austral). Santos Fernández, Carlos, Antonio López Ferreiro (1837-1910), Santiago de Compostela, Alvarellos; Consorcio de Santiago, 2013

Unamuno, Miguel de, La Dignidad Humana, 5ª ed., Madrid, Espasa-Calpe, 1961 (Col. Austral).

Zulaica Aristi, Daniel, Vida y obra del Dr. Madinaveitia, Guipúzcoa. Ed. Diputación Foral, 1985. 